\title{
The Impact of IT Development on Rural Communities in Korea
}

\author{
JUNGHOON MOON $^{* *} \cdot$ JOOWON PARK $^{* * *} \cdot$ GU HYUN JUNG $^{* * * * *}$ \\ and Young Chan CHOE
}

\begin{abstract}
The Internet has brought massive changes to human lives. Among the various positive and negative influences are the rural-urban digital divide, which refers to the information technology gap between rural and urban areas. The Korean government has made several efforts to close this digital divide. The main goal of this study is to identify how the personal and social lives of rural residents are affected by IT development in rural areas, and how the residents perceive the effect of IT development. To accomplish this goal, a survey research was conducted. A questionnaire was developed based on the current body of literature, and used to collect data. The questionnaire was distributed to rural residents in Korea and 272 responses out of a total of 300 collected were usable. Regression analysis methods were used for the analysis. On the analysis where the IT development index was used as an independent variable, positive relationships were found between the independent variables and some dependent variables such as perceived usefulness for jobs, IT usage skills, and tendencies of rural to urban migration. Findings show that rural residents are worried that IT development in rural areas may cause job loss in their respective communities, and decrease social interaction. However, positive perceptions were also apparent, as participants believed IT is useful for communications within the community, as well as better education and medical services.
\end{abstract}

Keywords: Digital Divide, IT Development, Rural Development

- This work was supported by the Korea Research Foundation Grant funded by the Korean Government (KRF-20-332-B060)

- Assistant Professor of Department of IT Business KAIST (Korean Advanced Institute of Science and Technology) 103-6 Munji-Dong, Daejeon, 305-732, Korea; Tel: 82-42-350-6308;

Fax: 82-42-350-6339; E-mail: jmoon@kaist.ac.kr

*.. Researcher of Department of IT Business KAIST (Korean Advanced Institute of Science and Technology) 103-6 Munji-Dong, Daejeon, 305-732, Korea; Tel: 82-42-350-6308;

Fax: 82-42-350-6339; E-mail: j_park@kaist.ac.kr

... Senior Researcher of Management Information Lab., Crops Research Division Gyeonggi Province Agricultural Research and Extension Services 315 Gisan-dong, Hwaseong-City, Gyeonggi Province, 445-300, Republic of Korea; Tel : 82-31-229-5786; Fax: 82-31-229-5965;

E-mail: igh1324@gg.go.kr

.... Professor of Division of Regional Information College of Agriculture and Life Sciences Seoul National University, San 56-1. Sillim-dong, Gwanak-gu.Seoul 151-742 Korea; Tel: +82-2-880-4743; Fax: +82-2-873-5080; E-mail:aggi@snu.ac.kr 


\section{INTRODUCTION}

T $\mathrm{T}$ development, especially increased access to the Internet, is attributed 1 with the continuously decreasing size of the world, along with improved knowledge-storing, sharing systems, and other useful applications (Akca, Sayili, and Esengun, 2007; Edwards and Eggers, 2004). Also, various experts engaged in diverse fields are taking advantage of the spread of the Internet (Guillén and Suárez, 2005). The Internet has created a new domain called 'cyberspace,' and those who have access to it can easily find resources containing valuable information, without much of the constraints of time and place (Hur, 2006). Even for some people, the Internet has become the central focus of their lives (Nalwa and Anand, 2003). According to Guillén (2005), various terms have been used to describe the effects of the Internet, such as "decentralizing, globalizing, harmonizing, and empowering" (681), "smaller, more open world" (681), "triumph over time and space" (681), "netizen" (681), and "customer as sovereign" (681).

According to Kwak et al. (2004), a number of questions have been raised by many experts, in accordance with the continuously growing popularity of the World Wide Web, and its consequences to human society (Norris, 2001). The various research questions on user attributes include internet usage duration, frequency, pattern, time spent online, and information processing, through which the researchers attempted to reveal the political and social consequences of the Internet (N. Kwak, Williams, Joo, and Wang, 2003; Nie and Erbring, 2000).

The consequences of technological innovations usually spread unevenly throughout society (Rogers, 1995), and therefore some groups are left behind. In spite of nearly universal access to the Internet, there are still some people who do not have Internet access. Kwak, et al. (2004) stated that this phenomenon raises the problem of access, information disparity, and knowledge gaps. This gap is called the "digital divide," and it exists upon diverse social variables, including household income, demographic difference, and regional difference (Prieger, 2003).

There have been many debates on the regional digital divide, especially with regard to the rural-urban gap. The most comprehensive statistical reports conducted by the U.S. Department of Commerce studies (e.g. NTIA, 2000, etc.) have stressed that there exists a remarkable digital divide between urban and rural areas (Parker, 2000; Skerratt and Warren, 2003). Globalization, information and communication revolution, and the increasing gap between urban and rural quality of life will gather momentum for major urbanization in the developing world in coming years (Biswas, 2006). In this sense, governments are making many efforts to provide broadband access for rural areas.

South Korea is known as one of the leading countries for high-speed broadband access, and for the rapid rate of increasing Internet availability in the world (Genus and Nor, 2005; Rhee and Kim, 2004) The Korean government has 
made a wide-ranging effort to bridge the rural-urban digital gap since the 1990s. As a result, even though the gap exists to some degree between rural and urban areas, IT infrastructure has been well established in the rural areas of Korea.

Do these efforts yield fruitful outcomes? At this point of time, it is necessary to explore the impact of IT development on the rural community in Korea. We will examine the impact of IT use, including the Internet, of rural residents regarding their attitude towards lives in their communities. Some of the previous studies assert that diffusion of IT use in rural areas will bring economic profits to these areas. Others also point out that construction of IT infrastructure in rural areas will assist the development of rural communities, and increase social linkage between residents in the communities through broadband (Leatherman, 2000; Min, Sukhumaran, and Varghese, 2001). However, while Internet use may enhance our communication positively and make it more convenient (Simmers, 2002), psychological well-being may be negatively affected (Kraut et al., 1998). Moreover, Internet use might encourage residents' migration to urban areas because they can easily find city jobs through the Internet, which can damage the traditional value of rural communities (Egan, 2002)

Which view, among two very different beliefs, gives the more likely prediction of the diffusion of IT use in rural communities? It is difficult to find prior studies dealing with its impact on the quality of life in rural communities at the personal level with empirical evidence. Therefore, it is necessary to explore with empirical methods the impact of IT use on the perception and behavior of residents who live in rural communities.

\section{DIGITAL DIVIDE}

In October 1993, the U.S. Department of Commerce adopted the goal of providing universal telecommunication and Internet access (NTIA, 1993). In 1997, the president declared a goal of wiring every home by the year 2007 (NTIA, 1998). A literature review found that among many factors associated with access to the "new information society" are income level, race, gender, education, and geographical location which have often been associated with social disadvantages. Some statistical analyses indicate that those factors are usually interrelated (e.g. Wilson, Wallin, and Reiser, 2003, etc.).

The main concept of the digital divide is a gap between those who are reaping the advantages of computers and the Internet, and those who are not (Wilson et al., 2003).

There have been mainly two debates on the digital divide (Hoffman and Novak, 1999): "Does it really exist?" and "If yes, is the gap going narrower, or wider?" A literature review finds that many prior studies have supported 
the fact that the digital divide exists, and that the debates on "gap changes" still remain heated.

The digital divide has been the central focus of a number of studies as it concerns not only the attributes of computer owners, but also the effective adaptation to the Internet, without which individuals and communities will face many difficulties to survive (Wilson et al., 2003). The definition of the term digital divide doesn't differ considerably from study to study. Maskery (2007) defined the term as "the subtle yet powerful discrimination caused by information and communications technology that is not accessible and usable by all individuals" (187). The social context of which the digital divide is frequently discussed is between the rich and poor, whites and minorities, and urban and rural areas. A report by the US Department of Commerce supports this fact by showing that Black and Hispanic households have lower rates of broadband access compared to white households. Likewise, rural residents have less access to the Internet than to urban residents, and poorer households have less access than to richer households. According to Prieger (2003), the Federal Communications Commission's findings also reveals the lower likelihood of broadband connection in rural and lower-income areas in the US, and concludes that "minority customers are vulnerable to not having access to advanced services in as timely a fashion as most other Americans" (346). Interest groups criticize the unequal opportunity of broadband access throughout the regions and the broadband carriers are further blamed for redlining.

The problem of uneven development of the Internet exists between countries. This phenomenon is called the "global digital divide." The proportion of the world population with Internet access is less than $10 \%$ of the whole population, and the gap has continuously grown since the early 1990s, showing notable differences between countries (Guillén and Suárez, 2005). Crenshaw, et al. (2006) stated that, considering that knowledge-based industries account for approximately half the economic production of OECD countries, advanced telecommunications are believed to be a necessity for economic and human development (UNDP, 2001). This confirms the importance of the "digital divide" as an area of research.

Since the present study focuses on a digital divide related to geographical location, an extended literature review was conducted in order to look over "gaps" between urban and rural areas. Urban residents are far more likely to have access to computer services, including broadband, than rural residents. Rural areas are often characterized by lower income and lower education levels of rural residents, which is known as one of the main causes of the late adoption of new technological innovations (McConnaughey and Lader, 1998; Whitacre and Mills, 2007).

Among the decisive causes of the rural-urban digital divide is the difference of broadband deployment among the regions (LaRose, Gregg, Strover, Straubhaar, and Carpenter, 2007). Min et al. (2001) and Skerrate and Warren (2003) point 
out that deployment of broadband in urban areas is widening the gap, rather than narrowing. In an assessment of rural IT infrastructure, rural areas are lagging behind urban areas in the availability of broadband. As geographic access is critical to the cost structure of Internet Service Providers (ISPs) which facilitate internet access (Leatherman, 2000), the problems of distance and low population densities hinder the diffusion of these technologies. For the companies to realize profit maximization, they need to focus their investments in rural areas where household incomes and population densities are higher (LaRose et al., 2007; Venkatachalam and McDowell, 2002).

Supporting the prior studies mentioned, Leatherman (2000) provides three general characteristics of rural areas that affect their access to use of IT. First, remote geography both increases costs associated with infrastructure diffusion and makes rural markets less attractive for outside investment. Second, the economic structure of rural areas seems a detriment insofar as their industries are neither heavily IT-producing nor IT-using. Finally human capital found in rural areas does not seem especially attractive either as a labor market or as a consumer market.

\section{IT DEVELOPMENT IN THE RURAL AREA OF KOREA ${ }^{1}$}

The Ministry of Food, Agriculture, Forestry and Fisheries (MIFAFF) in Korea has made an abundant effort to develop agricultural/rural informatization since the 1990s. The history of IT development for rural areas stemmed from the establishment of the Center for Agriculture Forestry Fisheries Information Service (AFFIS) in 1992. Since then, AFFIS, founded by MIFAFF, along with the Rural Development Administration (RDA), attempted to bridge the rural-urban digital divide and develop informatization of the food and agriculture industries.

The Ministry of Food, Agriculture, Forestry and Fisheries (MIFAFF) has focused on the development of three areas to bridge the digital gap between rural and urban areas: household personal computer (PC) penetration, Internet use, and broadband Internet connection accessibility.

In 1997 , the rate of household PC penetration was only $18.7 \%$ in the rural areas of Korea. MIFAFF established several policies to supply PCs to rural areas at a lower price or for free. For instance, MIFAFF, collaborating with other organizations in 2000, launched a campaign named "Sending PCs to Rural Areas" to supply PCs to households in rural areas for free. Many companies, as well as individuals, responded to the MIFAFF campaign by donating new or used PCs. Due to their efforts, the rate of household PC penetration in rural areas sharply increased up to $50.2 \%$ in 2006 . While the rate is still lower than that of urban areas $(79.6 \%)$, the gap has decreased.

The rate at which the Internet is used in rural areas has been continuously 
increasing since 1998 , when only $0.6 \%$ of those who worked in the agriculture industry used the Internet. As of 2006, the rate of users reached $29.4 \%$ and is still increasing. It should be addressed that a swift increase, from $0.6 \%$ to $16.2 \%$, was accomplished between 1998 and 2003 . This was not only due to the MIFAFF's campaign of "Sending PCs to Rural Areas," but also to the "Free Internet Connection Service," for rural residents carried out by AFFIS. Farmers could receive a PC for free or at a very low price and could connect to the Internet without any charge. Free education programs regarding computer/Internet use accompanied these notable policies. These customized informatization education programs were mainly designed and provided by AFFIS and RDA.

The accessibility to broadband Internet in rural areas was another big concern of the Korean government from the perspective of the digital divide. MIFAFF and MIC (Ministry of Information and Communication) requested that network-operating companies, putting up with low profitability, extend their network access to rural areas. As a result, the rate of broadband accessibility in rural areas increased from $81 \%$ in 2002 to $100 \%$ in 2007 . This number implies that anyone living anywhere in Korea can access high speed Internet anytime he or she wants.

Furthermore, the Korean government developed and distributed diverse software programs to farmers. These information systems were designed to support farmers' decision making. In 2007, MIFAFF financially supported 33 ERP (Enterprise Resource Planning) system development projects initiated by agricultural corporate bodies and agricultural product processing centers. MIFAFF currently facilitates them to adopt RFID (Radio-Frequency Identification) and sensor network technologies for their supply chain management based on a budget of 50 million USD.

\section{SURVEY}

The main goal of this study is to investigate the impact of IT development on the rural communities in Korea. To accomplish the goal, this study conducted a survey research.

A questionnaire form was developed based on the literature review (Appendix A). Likert scales (1-7), with anchors ranging from "strongly disagree" to "strongly agree," were used for most questions, except for five measurement items of the 'IT infrastructure index (Yes/No)'. For the 'IT infrastructure index,' 0.2 point for each "Yes" answer is given to the variable, and 0 point for each "No." A sum of five measurement items is used as IT infrastructure index score of each respondent, ranging from ' 0 ' to ' 1 .'

The questionnaire form was distributed to rural residents in Korea. The mailing 
list was collected from the Rural Development Administration (RDA) in Korea. The list includes more than 1,000,000 residents who have used administrative services from the RDA. We randomly selected about 3,000 from the list and sent a paper-based questionnaire to them.

A total of 302 responses were collected and 272 of them were usable. 30 out of 302 were deemed unusable, however. Some of them turned out to live in the metropolitan area at the time, while others had serious data missing or were considered outliers. Thus, a total of 272 responses were used for this analysis. Table 1 shows detailed information about the sample collected in this study.

Table 1. Profile of Sample Respondents

\begin{tabular}{|c|c|c|c|c|c|}
\hline \multicolumn{2}{|c|}{ Profile Category } & \multirow{2}{*}{$\frac{N}{206(75.7 \%)}$} & \multicolumn{2}{|c|}{ Profile Category } & $\mathbf{N}$ \\
\hline \multirow{2}{*}{ Gender } & Male & & \multirow{2}{*}{$\begin{array}{l}\text { Children at } \\
\text { schooling age }\end{array}$} & Yes & $142(52.2 \%)$ \\
\hline & Female & $59(21.7 \%)$ & & No & $119(43.8 \%)$ \\
\hline \multirow{6}{*}{ Age } & Lower than 20 & $3(1.1 \%)$ & \multirow{9}{*}{ Job } & Farming & $52(19.1 \%)$ \\
\hline & $21-30$ & $18(6.6 \%)$ & & Manufacturing & $7(2.6 \%)$ \\
\hline & $31-40$ & $57(21.0 \%)$ & & Service/sales & $58(21.3 \%)$ \\
\hline & $41-50$ & $92(33.8 \%)$ & & Public servant & $11(4.0 \%)$ \\
\hline & $51-60$ & $61(22.4 \%)$ & & Professional & $16(5.9 \%)$ \\
\hline & Higher than 61 & $36(13.2 \%)$ & & Business owner & $4(1.5 \%)$ \\
\hline \multirow{5}{*}{$\begin{array}{c}\text { Education } \\
\text { Level }\end{array}$} & Less than 9th grade & $15(5.5 \%)$ & & Housewife & $8(2.9 \%)$ \\
\hline & Some high school & $12(4.4 \%)$ & & Student & $3(1.1 \%)$ \\
\hline & High school grad & $93(34.2 \%)$ & & Unemployed/Others & $28(10.3 \%)$ \\
\hline & College graduate & $124(45.6 \%)$ & \multirow{6}{*}{$\begin{array}{c}\text { Number of } \\
\text { family } \\
\text { members }\end{array}$} & Lives alone & $\mathrm{l}(0.4 \%)$ \\
\hline & Graduate school & $19(7.0 \%)$ & & 2 & $13(4.8 \%)$ \\
\hline \multirow{8}{*}{$\begin{array}{l}\text { Annual } \\
\text { Household } \\
\text { Income } \\
\text { Level } \\
\text { (US \$) }\end{array}$} & Less than $20 \mathrm{~K}$ & $46(16.9 \%)$ & & 3 & $48(17.6 \%)$ \\
\hline & $20 \mathrm{~K}-30 \mathrm{~K}$ & $44(16.2 \%)$ & & 4 & $85(31.3 \%)$ \\
\hline & $31 \mathrm{~K}-40 \mathrm{~K}$ & $51(18.8 \%)$ & & 5 & $29(10.7 \%)$ \\
\hline & $41 \mathrm{~K}-50 \mathrm{~K}$ & $36(13.2 \%)$ & & 6 or higher & $15(5.5 \%)$ \\
\hline & $51 \mathrm{~K}-60 \mathrm{~K}$ & $27(9.9 \%)$ & \multirow{2}{*}{\multicolumn{2}{|c|}{$\begin{array}{l}\text { Daily computer use time (hours) } \\
\text { [S.D.] }\end{array}$}} & \multirow{2}{*}{$4.32 \mathrm{~h}[3.43]$} \\
\hline & $61 \mathrm{~K}-70 \mathrm{~K}$ & $15(5.5 \%)$ & & & \\
\hline & $71 \mathrm{~K}-80 \mathrm{~K}$ & $16(5.9 \%)$ & \multirow{2}{*}{\multicolumn{2}{|c|}{ Daily internet use time (hours) [S.D] }} & \multirow{2}{*}{$1.95 \mathrm{~h}[1.62]$} \\
\hline & Higher than $81 \mathrm{~K}$ & $21(7.7 \%)$ & & & \\
\hline
\end{tabular}

$75.7 \%$ of subjects were male and $21.7 \%$ were female. The age of respondents 
ranged from 18 to 73 years old, and most subjects were from 41 to 50 years old $(33.8 \%) .52 .2 \%$ of respondents answered that they have children at schooling age.

$21.3 \%$ of respondents' jobs were classified as customer service areas, and $19.1 \%$ into farming. The ratio of the category of 'farming' was extremely high considering that about $7 \%$ of Koreans are engaged in farming, according to the national census data of Korea. This is because the sample used in this study was collected in the rural area. Respondents whose annual household income is between $31 \mathrm{~K}$ and $40 \mathrm{~K}$ were most frequently observed in this sample (18.8\%). While in 2006 average annual household income in Korea turned out to be about $\$ 36,000$, the sample collected for this study shows that a large proportion of respondents $(19.1 \%)$ said that their annual household income is less than $\$ 20,000$.

Respondents answered that, on average, they use the computer 4.32 hours per day, and indicated that they use the Internet 1.95 hours per day, which is higher than the Korean national average of 1.71 hours per day. However, from the sample collected, 6 people answered that they do not use the Internet at all and 31 people answered that they use the Internet less than 30 minutes a day.

\section{THE RESULTS}

We used regression analysis methods for the analysis in this study. The IT development index discussed earlier is set as an independent variable. Each dependent variable, as shown in Appendix A, is used for each regression analysis. In addition, 'age' and 'annual household income' are set as control variables for relevant results (See Equation 1).

$$
Y_{i}=a+\beta_{1} X_{\text {index }}+\beta_{2} X_{\text {cont_age }}+\beta_{3} X_{\text {cont_income }}
$$

\section{THE IMPACT OF IT DEVELOPMENT ON PERSONAL LIFE IN THE RURAL COMMUNITY}

First of all, we investigate the usefulness of IT use for the jobs of rural residents by asking the following question, "Using the computer gets my work done in an easy and convenient way." It is found, through a regression analysis, that there is a positive relationship between the IT development index (independent variable) and the perceived usefulness (dependent variable). $45.1 \%$ of variance of the perceived usefulness of computer use is explained by the index ( $\beta=$ $.188, \mathrm{p}<.01)$ and the control variables -- age and annual household income. According to Lin et al. (2006), Davis et al. (1989) defined perceived usefulness 
as "the degree to which a person believes that using a particular system would enhance his or her job performance." Thus, it is concluded that rural residents believe that computer use enhances their job performance to some extent. The summary of this finding is also represented in Appendix A.

Next, the relationship between the playfulness of IT use and the IT development index are investigated by asking the question, "I think using the computer is fun." However, the index does not turn out to be a significant predictor of the dependent variable, i.e., entertainment. Fang et al. (2005/2006) defined perceived entertainment as "the degree to which a person believes that using a particular system would make him or her joyful." Therefore it can be concluded that rural residents don't find it fun to use computers. Also by combining the result from the questionnaires related to perceived usefulness and perceived entertainment, it can be assumed that the survey participants make use of computers more for working purposes rather than for entertainment purposes.

Another regression analysis was conducted using a dependent variable from the question, "I am very familiar in handling computer-related tasks." This dependent variable is related to the concept of computer self-efficacy. The result found that the index is a strong predictor of the computer self-efficacy $(\beta=$ $.189, \mathrm{p}<.01, \mathrm{R}^{2}=.342$ ). The rural residents who have higher IT accessibility develop stronger computer self-efficacy. As many previous studies in the area of business addressed, such feeling may yield better performance in their jobs in the future. Thus, it can be concluded that rural residents with a higher IT development index, that is, with better IT infrastructure in the community, have higher probability of better performance than others.

In addition, this study investigates the impact of IT development on migration intention. Migration intention is defined as an intention to leave for other areas in order to acquire a higher standard of living. This is contrary to the concept of an individual's intention to stay in the rural community and to continuously participate in social community activities as a community member. The question "I would like to move to an urban area" was asked to find out the relationship between the IT development index and rural-urban migration intention. It was found that as the IT development index is a strong predictor of the migration intention $\left(\beta=.182, p<.01, R^{2}=.334\right)$. In other words, the intention to move to urban areas is higher for those rural residents who own computers and have access to the Internet.

There are many studies addressing the reason behind the migration phenomenon. Fleisher and Yang (2006) viewed differences of income between the regions as a reason for the migration. In developing countries, governments' policies fostering speedy industrialization have discriminated against agricultural sectors and that has caused the two to three times higher income of urban households than the rural counterparts. Demir et al. (2006) stated urban-rural gaps in quality of life as a scimuli for the migration. People can access a higher level of education, 
better housing, higher chance of employment, improved health care, and infrastructure in urban areas. Sandikci et al. (2006) also listed several factors that are making rural life less genial such as limited work, mechanization, political disorder, and natural disasters, while factors making urban life more tempting such as social modernization, globalization, medical facilities, education, and cultural advantages.

In terms of the digital divide issue, many studies emphasized that IT development in rural areas would prevent rural residents' migration. The reasons given were that advanced IT infrastructure in rural areas would provide happiness for residents there, considering all economic, social, communication, welfare, and educational issues. However, there are some studies arguing that IT diffusion in rural communities will encourage residents' migration to urban areas because they can easily access more job opportunities in the urban area through internet use (Egan, 2002; LaRose, 2003).

This study asked the question, "I would like to move to an urban area," and investigated the relationship between this migration intention and the IT development index through a regression analysis. It is found that the index is a strong predictor of migration intention $\left(\beta=.182, \mathrm{p}<.01, \mathrm{R}^{2}=.334\right)$. The study finds that IT infrastructure development for rural communities enhances the tendency for residents to migrate to the urban areas in Korea.

\section{THE IMPACT OF IT DEVELOPMENT ON SOCIAL LIFE IN THE RURAL COMMUNITY}

This study also explored how social life in rural communities was impacted by the development of IT infrastructure. This study argues that IT development in rural areas must be related to both positive and negative perceptual potentials for rural communities. While many previous studies focused on positive effects of IT development in rural communities, other recent studies provide opinions absolutely contradictory to the mainstream. They are concerned with the negative effect of IT development in rural communities.

First of all, this study investigates the negative consequences that IT development may have brought to rural communities. As discussed earlier, several studies pointed out that IT development in rural areas does not always guarantee a promising future for the community. Along with enhanced migration to more urban areas, lower opportunities of employment in rural areas (LaRose, 2003) are addressed. In addition, psychological well-being and social involvement may be hampered by intensive internet usage (Jackson et al., 2004; Kraut et al., 1998). LaRose (2003) also warned that the highly vaunted community values of rural areas and trust between community members can be damaged through the excessive use of internet. 
In this regard, this study investigates rural residents' concerns about job loss due to over-development in the IT sector by asking the question, "I am concerned about job loss in my community due to IT development." The results of a regression analysis show that rural residents are worried about potential job loss in their communities due to the adoption of IT $\left(\beta=.157, \mathrm{p}<.05, \mathrm{R}^{2}=.202\right)$.

The next question is about the negative effects that IT has on well-being and amenities available in the rural area. The question, "Using the computer/Internet impairs well-being and happiness in my community" was asked to the respondents. However, the findings show that rural residents do not believe that IT development will hamper the well-being and happiness in the rural community $\left(\beta=.087, \mathrm{p}>.05, \mathrm{R}^{2}=.092\right)$.

In addition, we investigate whether or not the values of rural communities are hampered by IT development by asking, "Using the computer/Internet decreases social involvement due to IT use." The result of a regression analysis shows that rural residents are concerned about potential decrease of community involvement due to over-use of computers or access to the Internet $(\beta=.169$, $\mathrm{p}<.05, \mathrm{R}^{2}=.162$ ).

After exploring the perceived potential harms of IT development in the rural community by its residents, perceive, the study investigated the positive perceptions toward the role of IT use in their communities. Many studies, including projects sponsored by governments, have insisted that developing advanced IT infrastructure in rural areas will provide happiness for the residents there, with consideration to economic, social, communication, welfare, and educational issues.

To examine the positive effects of IT development on rural communities, this study asks three questions to the respondents. First, "Using the computer/Internet helps communications in my community" was asked, and the result implies that rural residents recognize the role of IT use for increased communication. IT use in the rural community can facilitate the quality and quantity of communication between community members $\left(\beta=.139, \mathrm{p}<.05, \mathrm{R}^{2}=.202\right)$.

The next question is associated with the role of IT use for improved standard of living ("Using the computer/Internet improves my standard of living in the community"). A regression analysis does not find a significant relationship between the IT development index and any improvement in one's standard of living $\left(\beta=.079, \mathrm{p}>.05, \mathrm{R}^{2}=.114\right)$.

The last question deals with the role of IT use for social welfare. The respondents were asked the question, "Using the computer/internet provides better education or medical service in my community." The results reflect the positive perception of rural residents' that IT use leads to improved opportunities of education and medical service in their communities. The IT development index turns out to be a statistically significant factor for the dependent variable, "perceived usefulness of IT use for better education and medical service $\left(\beta=.134, \mathrm{p}<.05, \mathrm{R}^{2}\right.$ $=.196)$." Students living in rural areas can access web pages where they can 
pay, and view lecture clips that are recorded in urban areas, resulting in similar educational opportunities as those in urban areas. Also, as it becomes easier for rural residents to search for information on medical institutions, chances of receiving proper medical services increases.

A summary of the findings from regression analyses is presented in Appendix A.

\section{CONCLUSIONS}

The rationale of this study was to explore the impact of IT development on rural communities in Korea. We examined the impact of IT use, including the Internet, and the attitude rural residents have towards lives in the community.

The influence of the Internet has been so great that along with its growing popularity, it has brought diverse changes in human life. The impact of the Internet, both positive and negative, has received continuous interest from researchers. One of the issues that have attracted researchers' attention is the digital divide, the problem of information disparity, and knowledge gaps incurred by unequal opportunity of Internet access. Although there are several other factors causing the digital divide, such as income level, race, or education level, this study focus on the digital divide between rural and urban areas. According to the literature review, urban residents are far more likely to have access to computers and broadband Internet access than do rural residents. It is argued that making broadband Internet accessible in rural areas would help close the gap in standard of living between rural and urban areas. This, would eventually slow down rural-urban migration, the main reason for this migration being the pursuit of a higher standard of living.

In South Korea, governmental institutions made continuous efforts to close the rural-urban digital divide. By sending free PCs to rural areas and providing free broadband Internet connection, they achieved 100\% broadband accessibility in Korea and succeeded in minimizing the rural-urban digital divide. They also developed and distributed software that was helpful to farmers. The findings of this study proves that these efforts helped rural residents as it was found that rural residents think computers are useful for their work and they are familiar with handling computer-related tasks.

Many previous studies showed that the reasons for rural to urban migration are usually related to a higher quality of life in urban areas, including higher chance of employment, higher income, better education, cultural amenities, and improved health care. Much of the literature on the urban-rural digital divide have shown that decreasing the urban-rural digital gap can improve employment conditions, educational levels, cultural amenities, and health care in rural areas. Analyzing the literature from the two fields brings us to the conclusion that 
minimizing the digital divide through IT development in rural areas could mitigate the migration tendencies of rural to urban areas. However, the outcome of this study shows somewhat opposite result. The findings show that the IT development index such as computer ownership and broadband accessibility are strong predictors of migration tendencies. Rural residents who own computers and have access to broadband Internet are more willing to leave their rural areas to urban areas than those who do not. To achieve the purpose of decreasing rural-urban migration through IT development in rural areas, government institutions should implement incentives for rural residents in order for them to stay in rural areas even after having access to IT.

The consequences of IT development on the attitude of rural residents have also been investigated. Many discussions exist between researchers on the impact of Internet usage on human life. While many of the previous studies focused on advantages that the Internet would bring about, recent studies have revealed some negative aspects of Internet use, mainly psychological ones. In this study, the results revealed that as a consequence of IT development, many people believed that the benefits conferred by such technology would bring improved communication in communities, and provide of better education or medical services. However, it should be carefully interpreted that the negative impact that IT can also cause, such as the psychological aspects respondents were worried about (e.g., decreased social involvement, decreased community value) can also be inferred as a result of overuse.

\section{REFERENCES}

Akca, Hasan, Murat Sayili, and Kemal Esengun. 2007. Challenge of rural people to reduce digital divide in the globalized world: Theory and practice. Government Information Quarterly 24(2): 404-413.

Biswas, Asit K. 2006. Editorial. Water Resources Development 22(2): 181-182. Crenshaw, Edward. M., and Kristopher. K. Robison. 2006. Globalization and the Digital Divide: The Roles of Structural Conduciveness and Global Connection in Internet Diffusion. SOCIAL SCIENCE QUARTERLY 87(1): 190-207.

Davis, Fred. D., Richard. P. Bagozzi, and Paul. R. Warshaw. 1989. User acceptance of computer technology: a comparison of two theoretical models. Management Science 35(8): 982-1003.

Demir, M. Hulusi, Meltem Ince, and Çi. 2006. The effects of Education and Urbanization on SAP. Problems and Perspectives in Management 4(2): 46-61.

Edwards, William. M., and Timothy. R. Eggers. 2004. Agricultural management e-school: Extension education over the Internet. American Journal of Agricultural Economics 86(3): 778-781.

Egan, Timothy. 2002, Nov. 6. Bill Gates view what he's shown in libraries. 


\section{New York Times Online Edition.}

Fang, Xiaowen, Susy Chan, Jacek Brzezinski, and Shuang Xu. 2005/2006. Moderating Effects of Task Type on Wireless Technology Acceptance. Journal of Management Information Systems 22(3): 123-157.

Fleisher, Belton. M., and Dennis Tao Yang. 2006. Problems of China's Rural Labor Markets and Rural-Urban Migration. The Chinese Economy 39(3): 6-25. Genus, Audley, and Mohd Ali Mohamad Nor. 2005. Socialising the digital divide: Implications for ICTs and E-business development. Journal of Electronic Commerce in Organizations 3(2): 82-94.

Guillén, Mauro F. and Sandra L. Suárez. 2005. Explaining the Global Digital Divide: Economic, Political and Sociological Drivers of Cross-National Internet Use. Social Forces 84(2): 681-708.

Hoffman, Donna L. and Thomas P. Novak. 1999. The growing digital divide: Implications for an open research agenda. from http://ecommerce.vanderbilt.edu. Hur, Mann Hyung 2006. Demographic, Habitual, and Socioeconomic Determinants of Internet Addiction Disorder: An Empirical Study of Korean Teenagers. CYBERPSYCHOLOGY and BEHAVIOR 9(5): 514-525.

Jackson, Linda A., Alexander von Eye, Gretchen Barbatsis, Frank Biocca, Hiram E. Fitzgerald, and Yong Zhao. 2004. The impact of internet use on the other side of the digital divide. Communications of the ACM 47(7): 43-47.

Kraut, Robert, Michael Patterson, Vicki Lundmakr, Sara Kiesler, Tridas Mukopadhyay, and William Scherlis. 1998. Internet Paradox: A social technology that reduces social involvement and psychologlical well-being? American Psychologist 53: 1017-1032.

Kwak, Nojin, Marko M. Skoric, Ann E. Williams, and Nathaniel D. Poor. 2004. To Broadband or Not to Broadband: The Relationship Between High-Speed Internet and Knowledge and Participation. Journal of Broadcasting and Electronic Media 48(3): 421-445.

Kwak, Nojin, Ann Williams, Sung-Hee Joo, and Xiaoru Wang. 2003. A multidimensional approach to socio-political Internet use: Patterns of internet use, informal associations, and public affairs participation. Paper presented at the annual meeting of the Association for Education in Joumalism and Mass Communication. Kansas City, MO.

LaRose, Robert. 2003. Closing the rural broadband gap: A call for program evaluation: Quello Center for Telecommunications Management and Law, MSU.

LaRose, Robert, Jennifer L. Gregg, Sharon Strover, Joseph Straubhaar, and Serena Carpenter. 2007. Closing the rural broadband gap: Promoting adoption of the Internet in rural America. Telecommunications Policy 31(6-7): 359-373.

Leatherman, John. C. 2000. Internet-based commerce: Implications for rural communities: U.S. Economic Development Administration.

Lin, Cien-Huang and Shu-Fen Yu. 2006. Consumer Adoption of the Internet as a Channel: The Influence of Driving and Inhibiting Factors. Journal of 
American Academy of Business, Cambridge 9(2): 112-117.

Maskery, Helen 2007. Crossing the Digital Divide-Possibilities for Influencing the Private-Sector Business Case. The Information Society 23: 187-191.

McConnaughey, James, and Wendy Lader. 1998. Falling through the Net II: New data on the digital divide. National Telecommunications and Information Administration.

Min, Jo, Balaji Sukhumaran, and Siju Varghese. 2001. Internet-based economic development for rural communities: U.S. Economic Development Administration.

Nalwa, Kanwal, and Archana Anand. 2003. Internet Addiction in Students: A Cause of Concern. CyberPsychology and Behavior 6(6): 653-656.

Nie, Norman H., and Erbring, Lutz. (2000). SIQSS Internet and society study. Stanford, CA: Stanford Institute for the Quantitative Study of Society.

Norris, Pippa. (2001). Digital divide: Civic engagement, information poverty and the Internet worldwide. New York Cambridge University Press.

NTIA. (1993). National information infrastructure: Agenda for action: National Telecommunication and Information Administration.

NTIA. (1998). Falling through the Net II: New data on the digital divide: National Telecommunication and Information Administration.

NTIA. (2000). Falling through the net: towards digital inclusion: National Telecommunication and Information Administration.

Parker, Edwin B. 2000. Closing the digital divide in rural America. Telecommunications Policy 24: 281-290.

Prieger, James. E. 2003. The supply side of the digital divide: Is there equal availability in the broadband internet access market? Economic Inquiry 41(2): 346-363.

Rhee, Kyung Yong, and Wang-Bae Kim. 2004. The adoption and use of the internet in South Korea. Journal of Computer Mediated Communication 9(4): http://jcmc.indiana.edu/vol9/issue $4 /$ rhee.html.

Rogers, Everett M. 1995. Diffusion of innovations.

Simmers, Claire A. 2002. Aligning Internet Usage with Business Priorities. Communications of the ACM 45(1): 71-74.

Skerratt, Sarah, and Martyn Warren. 2003. Broadband in the countryside: the new digital divide. EFITA 2003 Conference 484-491.

UNDP. 2001. Human Development Report. New York: Oxford University Press.

Venkatachalam, Shree, and Stephen D. McDowell. 2002. What is broadband? What is rural? Government Information Quarterly 20: 151-166.

Whitacre, Brian E., and Bradford F. Mills. 2007. Infrastructure and the rural-urban divide in high-speed residential Internet access. International Regional Science Review 30(3): 249-273.

Wilson, Kenneth R., Jennifer S. Wallin, and Christa Reiser. 2003. Social stratification and the digital divide. Social Science Computer Review 21(2): 133-143. 


\section{Appendix A. QUESTIONNAIRE ITEMS}

\begin{tabular}{|c|c|c|c|}
\hline Variable & Items & $\beta$ & $\mathbf{R}^{2}$ \\
\hline $\begin{array}{l}\text { IT } \\
\text { Development } \\
\text { Index } \\
\text { (Independent } \\
\text { variable) }\end{array}$ & $\begin{array}{l}\text { - Home computer ownership }(\mathrm{Y} / \mathrm{N}) \\
\text { - In-house Internet access }(\mathrm{Y} / \mathrm{N}) \\
\text { - Home broadband availabilities }(\mathrm{Y} / \mathrm{N}) \\
\text { - Home broadband use }(\mathrm{Y} / \mathrm{N}) \\
\text { - Adjacent public places for Internet and computer use }(\mathrm{Y} / \mathrm{N})\end{array}$ & \multicolumn{2}{|c|}{$\mathrm{N} / \mathrm{A}$} \\
\hline $\begin{array}{l}\text { Dependent } \\
\text { variables }\end{array}$ & $\begin{array}{l}\text { - Using the computer gets my work done in an easy and } \\
\text { convenient way } \\
\text { - I think using the computer is fun } \\
\text { - I am very familiar in handling computer-related tasks. } \\
\text { - I would like to move to an urban area } \\
\text { - I am concerned about job loss in my community due to IT } \\
\text { development } \\
\text { - Using the computer/Internet impairs well-being and happiness } \\
\text { in my community } \\
\text { - Using the computer/Internet decreases social involvement due } \\
\text { to IT use } \\
\text { - Using the computer/Internet helps communication in my } \\
\text { community } \\
\text { - Using the computer/Internet improves living quality in my } \\
\text { community } \\
\text { - Using the computer/Internet provides better education or } \\
\text { medical services in my community }\end{array}$ & $\begin{array}{l}.188^{\circ} \\
.011 \\
.189^{\circ} \\
.182^{\circ} \\
.157^{\circ} \\
.087^{\circ} \\
.169^{\circ} \\
.139^{\circ} \\
.079^{\circ} \\
.134^{\circ}\end{array}$ & $\begin{array}{l}.451 \\
.172 \\
.342 \\
.334 \\
.202 \\
.092 \\
.162 \\
.202 \\
.114 \\
.196\end{array}$ \\
\hline $\begin{array}{l}\text { Control } \\
\text { variables }\end{array}$ & $\begin{array}{l}\text { Annual household income } \\
\text { Age }\end{array}$ & \multicolumn{2}{|c|}{ N/A } \\
\hline
\end{tabular}




\section{ENDNOTES}

' All information in this chapter was presented by the Informatization Support Team of MIFAFF. 